\title{
A formação humana no pós-humanismo: reflexões a partir da Carta sobre o humanismo de Heidegger
}

\author{
Human formation in post-humanism: \\ reflections about Heidegger's Letter on Humanism
}

Marcelo José Doro

Professor Doutor na Universidade de Passo Fundo, Passo Fundo, Rio Grande do Sul, Brasil. marcelodoro@upf.br - http://orcid.org/0000-0001-9765-1958

Recebido em 09 de outubro de 2018

Aprovado em 12 de setembro de 2019

Publicado em 15 de maio de 2020

\section{RESUMO}

Este artigo atém-se à discussão do problema da formação humana em um contexto pós-humanista, tendo como escopo o pensamento de Martin Heidegger. Em um primeiro momento, busca-se reconstruir os principais pontos da crítica heideggeriana ao humanismo, focando no vínculo deste com uma compreensão metafísica da essência humana. Em um segundo momento, tenta-se explorar as possibilidades formativas que se originam com a própria crítica de Heidegger à metafísica e ao humanismo, momento em que o pensamento do ser proposto pelo filósofo é tomado como indicativo central para uma concepção do ser humano que tenha por base o efetivo envolvimento deste com a realidade histórica que o abarca. O objetivo é marcar uma nova perspectiva para a formação humana, a qual esteja desvinculada de quaisquer ideais fixos e possa, assim, favorecer mais bem a riqueza indeterminada das possibilidades do acontecer humano no mundo. Situada para além das pretensões metafísicas de afirmar uma natureza intrínseca ou uma teleologia extrínseca ao acontecer humano, essa nova perspectiva formativa mostra-se mais apropriada e mais respeitosa em relação às diferenças constitutivas das sociedades democráticas plurais do mundo ocidental contemporâneo.

Palavras-chave: Pós-humanismo; Formação humana; Heidegger.

\section{ABSTRACT}

This paper focuses on the discussion of the human formation issue in a post-humanist context, with Martin Heidegger's work as its scope. Firstly, the reconstruction of the Heideggerian critique to the humanism main points is sought, focusing in its link with a metaphysical understanding of the human essence. Secondly, the formative 


\section{T usm

ISSN: 1984-6444 | http://dx.doi.org/10.5902/1984644435113

possibilities opened by Heidegger's own critique of metaphysics and humanism are explored. The thought of being, proposed by the philosopher, is taken as the central indicative for a conception of the human being based on the effective involvement of the latter with the historical reality that encompasses it. The aim is to mark a new perspective for human formation unrelated to any fixed ideals, which, thus, can better favor the indeterminate wealth of possibilities of the human happening in the world. Situated beyond the metaphysical pretensions of affirming an intrinsic nature or a teleology extrinsic to human events, this new formative perspective proves to be more appropriate and more respectful of the constitutive differences of the plural democratic societies in the contemporary Western world.

Keywords: Post-humanism; Human formation; Heidegger.

Lo que me asusta del humanismo es que presenta cierta forma de nuestra ética como modelo universal para cualquier tipo de libertad. Me parece que hay más secretos, más libertades posibles y más invenciones en nuestro futuro de lo que podemos imaginar en el humanismo [...].

(FOUCAULT, 2008, p. 150)

\section{Introdução}

O discurso pós-humanismo, que ganhou fôlego a partir da segunda metade do século XX, tem como marco fundamental de sua constituição a Carta sobre 0 humanismo que Martin Heidegger escreveu em resposta a Jean Beaufret, um jovem professor de filosofia francês. O texto foi redigido no outono de 1946, imediatamente após a Segunda Guerra Mundial, momento em que ganhavam força questões sobre como a civilização moderna, supostamente iluminada pela razão, poderia ter produzido as barbáries que o mundo acabava de testemunhar. O humanismo, como sempre acontece em tempos de barbárie, voltava à pauta, mas pesava sobre ele a desconfiança que, no geral, pesava também sobre o conjunto da tradição ocidental. É nesse contexto que Beaufret questiona Heidegger sobre como se poderia devolver um sentido a palavra "humanismo" (HEIDEGGER, 2005, p. 11).

A Carta sobre o humanismo é uma resposta à questão formulada por Beaufret. Mas não se trata de uma resposta circunstancial, que se limita a refletir o contexto (muito) específico em que se encontravam os interlocutores. Se, por um lado, é verdade que "Heidegger liga-se de modo quase frenético aos eventos que o rodeiam" 


\section{Buthapẫ}

ISSN: 1984-6444 | http://dx.doi.org/10.5902/1984644435113

(STEIN, 2011, p. 74), por outro, não é menos verdade que ele se empenha na identificação da estrutura ontológica de tais eventos. E isso vale exemplarmente para a discussão acerca do humanismo. Para além de meras considerações epocais, a Carta de Heidegger pensa as condições de possibilidade do humanismo e, ao fazêlo, "inaugura um novo espaço trans-humanista ou pós-humanista, dentro do qual tem se movido desde então uma parte essencial da reflexão filosófica acerca do ser humano" (SLOTERDIJK, 2007, p. 7).

A contribuição principal deste escrito volta-se, justamente, para esse espaço trans- ou pós-humanista que a reflexão de Heidegger inaugura, a partir do qual buscam-se caminhos alternativos para se pensar a formação humana na atualidade. Que ainda se possa falar em formação humana num contexto pós-humanista, isso depende da correta interpretação da crítica ao humanismo como promoção e não como combate do ser humano. Pensa-se contra o humanismo, diz Heidegger (2005, p. 33), precisamente "porque ele não instaura a humanitas do ser humano numa posição suficientemente alta".

Seguindo essa orientação, a primeira parte deste escrito apresenta um esforço de reconstrução dos principais pontos da crítica de Heidegger ao humanismo, focando no vínculo deste como uma compreensão metafísica da essência humana. A segunda parte explora as possibilidades formativas que se abrem a partir da crítica à metafísica e ao humanismo; e, nesse ponto, torna-se central a via interpretativa aberta por Gianni Vattimo (2016), que vê na proposta heideggeriana de "superação da metafísica" um apelo para que o ser humano se empenhe concretamente em favor da comunidade histórica a que pertence.

O objetivo é marcar uma perspectiva de compreensão da formação humana desvinculada de ideais fixos, que conserve a riqueza indeterminada das possibilidades do acontecer humano no mundo. Nessa direção, o pensamento do ser proposto por Heidegger (2005) é tomado como indicativo central para a construção do ser humano desde seu efetivo envolvimento com a realidade histórica que o abarca. $\mathrm{Na}$ perspectiva oferecida por Heidegger, é o pensamento do ser que abre aos indivíduos a compreensão mais radical de suas possibilidades existenciais (caminhos para sua 


\section{F HWM Eullataáo

ISSN: 1984-6444 | http://dx.doi.org/10.5902/1984644435113

autoformação) e, ao mesmo tempo, compromete-os com uma proposta política que desautoriza visões fechadas acerca do ser humano e da sociedade.

\section{A metafísica, o humanismo e a essência humana}

O que é dito na Carta sobre o humanismo, em relação à essência humana, à metafísica, à diferença ontológica e até mesmo em relação ao humanismo, é expressão de um entendimento que veio se constituindo há tempo e que remonta, em parte, a obra capital de Heidegger, Ser e tempo (1986). Em vista disso, torna-se oportuno à boa compreensão das formulações da Carta a recuperação dos principais passos desse percurso.

A questão diretriz que mobiliza o pensamento de Heidegger, e que é também a questão de fundo de sua crítica ao humanismo, refere-se ao esquecimento do ser na tradição filosófica. Dito de um modo mais preciso, a tradição filosófica não esqueceu o ser, senão que passou a pensá-lo a partir dos entes, enquanto aquilo que se mostra em si mesmo, a partir de si mesmo, e que pode ser reconhecido pela razão em sua consistência ontológica (HEIDEGGER, 1986, p. 2-4). Assumido esse pressuposto, coube à filosofia a tarefa de reconhecer e fixar a identidade essencial dos entes por meio de definições racionais. E uma vez fixado o ser dos entes a partir das definições, a filosofia buscou explicá-los desde um fundamento último. Foi assim que o esforço filosófico para capturar a realidade em sua forma essencial se transformou naquilo que, mais tarde, Heidegger chamou de "onto-teo-logia", ou seja, um modo de pensar a realidade que busca representar os entes em seus traços mais gerais e, ao mesmo tempo, explicá-los a partir de sua fundamentação em um ente supremo (HEIDEGGER, 1999a, p. 191).

Pois bem, esse modo de pensar que foi introduzido por Platão e que se tornou a matriz do pensamento filosófico ocidental até Nietzsche, na medida em que tomou como referência o ente e buscou reconhecer o ser na constância de seus elementos mais gerais e na sua pertinência a uma ordem de fundamentação totalizadora, acabou por desviar-se da pergunta pelo ser enquanto tal. Em outra palavras, ao pensar o ser a partir dos entes, a tradição filosófica deixou de perguntar pelo ser enquanto aquilo 


\section{F HWM \\ 15SN: 1984-6444

ISSN: 1984-6444 | http://dx.doi.org/10.5902/1984644435113

que, não sendo um ente, suporta o aparecer dos entes em seu ser. O fato é que, apesar de toda a investigação ontológica, não se atentou para o sentido do ser enquanto tal. "Sentido" - explica Heidegger (1986, p. 151) - "é aquilo em que se detém a compreensibilidade de algo". Nessa perspectiva, surge Ser e tempo com sua ontologia fundamental: o objetivo declarado da obra é justamente recolocar a pergunta pelo sentido do ser (HEIDEGGER, 1986, p.1), enquanto aquilo que se dá à compreensão humana antes de toda e qualquer relação com os entes (HEIDEGGER, 1986, p. 6). E, justamente por isso, é que a pergunta pelo sentido do ser, enquanto pergunta pelas condições de possibilidade da relação com os entes, precisa ser reconhecida como anterior à pergunta pelo que são os entes em sua constituição essencial.

O sentido do ser não pode ser dito em uma definição; pode apenas ser pensado em seu sentido (HEIDEGGER, 1986, p. 4), o que o filósofo tentará fazer por meio do conceito de tempo - daí o título "ser e tempo". Em linhas (bem) gerais, sua tese é de que o sentido do ser articula-se historicamente, quer dizer, acontece de modo temporal. Para colocar isso em uma linguagem menos heideggeriana, pode-se partir da constatação de que toda relação do ser humano com o mundo já é sempre uma relação a partir do mundo, de modo que essa relação é invariavelmente mediada por uma forma de compreender as coisas que depende do próprio contexto em que aquele que compreende está inserido. Não há, por assim dizer, uma forma de acesso ao mundo que seja isenta de influência, como um tipo de visão sem perspectiva; o mundo, enquanto totalidade significativa em que a vida se desenvolve, já é sempre um mundo humano e, não obstante, os humanos só podem existir enquanto produtos desse mundo. É no interior desse círculo apropriativo ${ }^{1}$ que o ser humano se constitui como indivíduo e recolhe os parâmetros de todo comportamento e conhecimento possíveis. Não há posição alguma que seja neutra. Como já constatou Nietzsche (2013, p. 262), tudo é interpretação.

Antes de Heidegger, Kant (1983) já havia mostrado que, para conhecer o mundo, o ser humano precisa de certas estruturas a priori que não podem ser excluídas da experiência e que são o próprio princípio de organização da experiência. Mas Kant, assim como boa parte dos neokantianos, pensava nessas estruturas a priori 


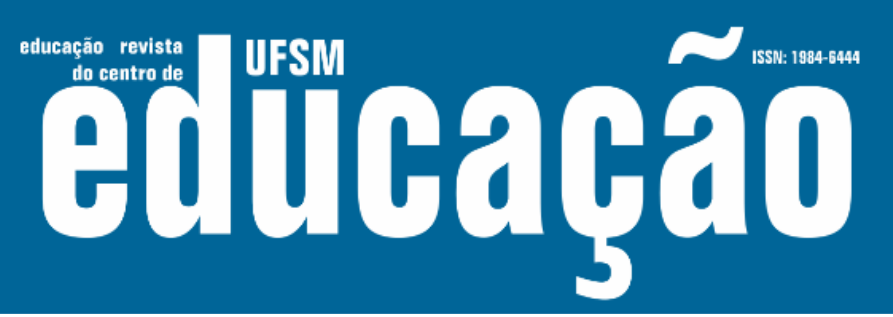

ISSN: 1984-6444 | http://dx.doi.org/10.5902/1984644435113

como categorias da razão, que eram para ele sempre iguais e iguais para todos. Heidegger, por sua vez, entende que os a priori que possibilitam ao ser humano experienciar o mundo não se encontram em uma estrutura racional pura e universal, mas no próprio mundo. Nesse sentido, pode-se dizer que Heidegger é um kantiano que incorporou as descobertas da antropologia cultural sobre como culturas e sociedades diferentes interpretam o mundo a partir de pressupostos estruturais específicos. Ao mesmo tempo em que se constitui a si mesmo no interior de mundo histórico-cultural, o ser humano incorpora os esquemas de significados constitutivos desse mundo, que serão a base de toda sua experiência e de toda sua ação.

A linguagem é o elemento determinante desse todo significativo que Heidegger chama de mundo. Ela é o elemento estrutural que fornece, em cada caso e em cada época, a rede de significância a partir da qual as coisas do mundo e os fatos da vida se tornam inteligíveis, ou seja, se mostram para o ser humano como significativos. Por isso, a linguagem será declarada, na Carta, como "a casa do ser" (HEIDEGGER, 2005, p. 8), ou seja, como o a priori disso que se mostra ao ser humano como "realidade". Nessa perspectiva, também o ser humano pertence à linguagem, no sentido de que suas possibilidades de autocompreensão e autoformação estão atreladas à realidade que a cada vez se abre ou se fecha com a linguagem.

A tradição filosófica, que Heidegger (2005) identifica como Metafísica, na medida em que pensou o ser a partir do ente (quer dizer, como o aspecto geral do ente) e se esqueceu de perguntar pelo sentido do ser (enquanto aquilo que suporta o aparecer do ente em sua identidade), acabou seguindo um caminho equivocado de interpretação do ser humano e da linguagem. O primeiro dos equívocos foi (tentar) explicar o ser humano usando as mesmas categorias empregadas para explicar os entes, de onde nasceu a definição tradicional do "animal racional", que constitui, segundo Heidegger (2005, p. 21), o pano de fundo de todos os humanismos da tradição. O segundo equívoco é decorrência do primeiro e consiste na interpretação da linguagem como uma propriedade do ser humano, um meio de expressão da racionalidade (HEIDEGGER, 2005, p. 28). Não que seja inteiramente errado pensar a linguagem e o próprio ser humano a partir da racionalidade, o problema é que, por 


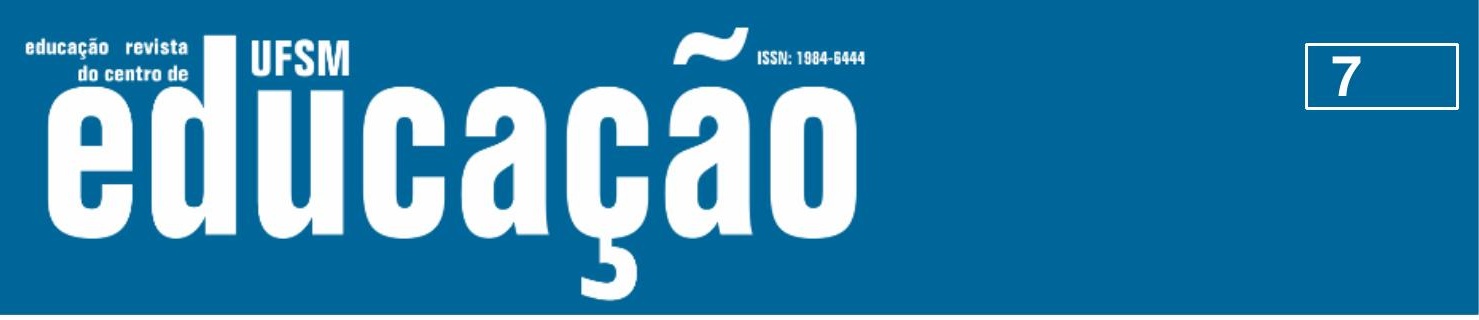

ISSN: 1984-6444 | http://dx.doi.org/10.5902/1984644435113

esse caminho, no entender de Heidegger, não se alcança uma compreensão suficientemente ampla do que está em questão.

Na visão de Heidegger (2005, p. 25-29), o que estabelece a mais alta dignidade da condição humana é o seu pertencimento ao ser, ou melhor, ao sentido do ser. Nesse pertencimento reside a mais radical liberdade, enquanto abertura para aquilo que dá ao ser humano o estofo a partir do qual seu futuro é construído. Pensado a partir do tempo, o ser é articulação por excelência; é articulação de significados que se opera na linguagem viva de um povo. E é na pertença atenta a essa articulação que o ser humano se faz livre, fundamentalmente livre, no sentido de poder significar as possibilidades de seu destino. Isso é o que quer dizer, para o ser humano, existir (ex-sistir): desdobrar-se para fora de si na abertura do sentido do ser, ou seja, formar a si mesmo a partir das possibilidades do mundo. Existir é ser no aí que constitui o mundo; existir é ser-no-mundo, é ser-aí (Dasein).

$\mathrm{Na}$ insistência de Heidegger em reafirmar a existência como "substância" do ser humano, repetida tantas vezes em Ser e tempo e depois retomada na Carta, ${ }^{2}$ mostra-se uma reação clara ao movimento típico da filosofia tradicional de buscar o ser e a verdade em níveis superiores de fundamentação. Platão foi o precursor desse jeito tradicional de pensar que Heidegger vai identificar como metafísico. Ele buscou a verdade das coisas sensíveis nas ideias a que elas correspondem e, depois, fundou estas ideias em uma de ordem superior, a ideia de bem. Ao falar de existência, Heidegger (2005) rompe esse modelo metafísico de determinação das essências pela remissão a um nível superior, remetendo à faticidade do mundo histórico em que o ser humano constitui-se a cada vez como fundamento sem fundo de toda verdade (essa é uma constatação importante para a reflexão sobre a formação humana que será desenvolvida na segunda parte deste escrito). E é nessa direção que a crítica ao humanismo, do jeito que Heidegger o interpretou, torna-se inevitável. Pois o humanismo, que teve seu o início junto com a metafísica, ao assumir a tarefa de conduzir o ser humano às suas possibilidades superiores, fazendo com que a racionalidade do animal racional se sobrepusesse a sua animalidade, o faz invariavelmente a partir de um ideal humano projetado em um nível superior, desconectado da história. Para Heidegger (2008, p. 248), isso se dá, historicamente, 


\section{Autกaหูão}

ISSN: 1984-6444 | http://dx.doi.org/10.5902/1984644435113

"pela cunhagem de uma postura 'ética', como redenção da alma imortal, como desenvolvimento das forças criativas, como aperfeiçoamento da razão, como cuidado da personalidade, como despertar do senso comum, como disciplina do corpo" ou ainda, acrescenta ele, "como acompanhamento adequado de um ou de todos esses 'humanismos'. A cada vez traça-se um círculo determinado metafisicamente ao redor do homem, em uma órbita mais ampla ou mais estreita".

$\mathrm{Na}$ Carta sobre o humanismo, é reforçada essa ideia de que os vários humanismos se distinguem ao adotarem concepções específicas de "liberdade", de "natureza humana" ou de "mundo", mas, no geral, conservam sempre a postura metafísica de eleger um ideal de humanidade atemporal para ser promovido em oposição ao inumano, ao bárbaro (HEIDEGGER, 2005, p. 17-20). Para ilustrar sua constatação, Heidegger recorda que o primeiro humanismo, o romano, almeja a elevação da virtude mediante a incorporação da paideia herdada dos gregos, sendo determinado pelo ideal do homem sábio. O humanismo cristão, que compreende a natureza humana a partir de sua relação com Deus, propõe a liberação do homem para o divino. Na Renascença, quando renasce o humanismo romano (e, portanto, a paideia grega), o ser humano é mais uma vez pensado a partir da elevação cultural, pelo que se busca novamente valorizar da instrução como antídoto da barbárie. $O$ humanismo de Marx, que determina a essência humana a partir da sociedade, busca assegurar a efetiva realização do ser humano pela edificação de uma sociedade determinada em que suas necessidades naturais possam ser atendidas. Por fim, também o existencialismo que Sartre, ainda que se levante contra o essencialismo, permanece metafísico, porque não consegue ultrapassar o pressuposto básico da compreensão do ser humano como em ente acrescido de propriedades; quer dizer, o existencialismo de Sartre continua alheio à existência enquanto abertura para o ser possível no mundo (HEIDEGGER, 2005, p. 30-31).

Em suma, a crítica de Heidegger ao humanismo, ou aos humanismos, volta-se à limitação da metafísica em pensar o ser humano de outra forma a não ser com base nas mesmas categorias usadas para explicar os entes não humanos. O problema é que esse caminho de pensamento acaba conduzindo a determinados ideais, que mesmo desconectados da história, são postos no horizonte de realização do ser 


\section{N HEM otlltaráo

ISSN: 1984-6444 | http://dx.doi.org/10.5902/1984644435113

humano histórico. Dessa forma, "a metafísica fecha-se à simples noção essencial de que o homem somente desdobra o seu ser na sua essência, enquanto recebe o apelo do ser" (HEIDEGGER, 2005, p. 23). O humanismo, que cresce e constitui-se metafisicamente alheio a questão do ser, é o responsável, nesse sentido, por ocultar um não-pensar de vinte séculos: com seus pressupostos apressados, suas definições aparentemente evidentes e inevitáveis da essência humana, tem continuamente impedido, no entender de Heidegger (2005), o surgimento da autêntica pergunta pelo ser humano, a pergunta pelo ser humano em sua correspondência ao acontecer histórico do mundo.

\section{Pós-humanismo e formação humana}

Há um esforço considerável de Heidegger, na Carta, para desfazer malentendidos que poderiam surgir a partir de sua reflexão. Porque se fala contra o humanismo, alerta ele, alguém pode concluir daí uma defesa do inumado e uma glorificação da barbárie (HEIDEGGER, 2005, p. 58). O equívoco de uma interpretação assim é do mesmo tipo que considera o discurso contra a lógica uma renúncia ao rigor do pensamento; ou que toma a fala contra os valores como um desprezo em relação aos bens supremos da humanidade. Esse tipo de pensamento simplista assume que todo falar contra é uma recusa negativa do que está em questão e, assim, bloqueia uma visão mais livre das coisas. Superados esses preconceitos, há de ficar mais claro que "a oposição ao 'humanismo' não implica, de maneira alguma, a defesa do inumano”, ela apenas “abre outras perspectivas” (HEIDEGGER, 2005, p. 61).

As "outras perspectivas" de que fala Heidegger surgem justamente porque a crítica ao humanismo não cancela o interesse pela humanitas. Ao contrário, a crítica trata de colocar o interesse pelo ser humano a partir de sua pertinência ao ser e, assim, pensar a humanitas em sua mais alta dignidade. Por essa via, inclusive, é que deve ser interpretada a analítica existencial e o discurso acerca do cuidado (Sorge) que perpassam Ser e tempo: como um esforço para reconduzir o ser humano novamente para a sua essência. ${ }^{3}$ Nessa obra, o interesse pela humanitas revela-se em sua forma mais originária; ali, o autêntico humanismo ${ }^{4}$ é promovido, enquanto 


\section{Authaหูão}

ISSN: 1984-6444 | http://dx.doi.org/10.5902/1984644435113

empenho em "meditar e cuidar para que o ser humano seja humano e não desumano, inumano, isto é, situado fora da sua essência" (HEIDEGGER, 2005, p. 17). Os humanismos históricos fracassam nesse propósito por conta da sua orientação metafísica, que determina a humanitas do ser humano a partir do ponto de vista de uma interpretação fixa da natureza, da história, do mundo e de seu fundamento, ou seja, do ponto de vista do ente na sua totalidade.

Compreendido o ataque de Heidegger ao humanismo desde o contexto de sua crítica à metafísica, não é custoso acompanhá-lo na reivindicação de que se pense o ser humano para além do modelo essencialista dos humanismos tradicionais. Essa reivindicação se faz ainda mais urgente diante da constatação do filósofo de que há um perigo inerente à consumação da metafísica em curso nas sociedades tecnológicas contemporâneas, perigo esse que não advém do potencial bélico dos produtos da técnica, mas de sua essência.

Por essência da técnica, Heidegger (2006a) designa a força histórico-cultural (Gestel, composição) que mobiliza os seres humanos a explorar o mundo e a descobrir, por meio da exploração, a natureza e tudo o que integra o mundo cultural como recurso disponível ao fazer humano. Tudo converte-se em objeto diante da vontade incondicionada do sujeito mobilizado pela essência da técnica. A realidade como um todo é, então, experimentada sob o caráter da objetificação. Por toda parte, só o que se percebe são objetos de investigação, manipulação, organização. No limite, apenas o que é objeto é tomado como real. O mundo já não se mostra senão como uma trama causal e relacional de objetos, onde tudo tem lugar, função e razão. ${ }^{5}$ Inserido nessa composição, o próprio ser humano passa a se compreender a partir da pertinência a esse mundo objetificado; e nem mais se espanta que se fale abertamente, e em toda parte, de "material humano" e de "recursos humanos".

$O$ perigo inerente a esse modo técnico de ser e de compreender é a possibilidade de o ser humano acabar preso a essa abertura interpretativa de mundo, tornando-se incapaz de pensar diferente e, consequentemente, de agir diferente para transformar sua realidade imediata. Frente a esse perigo, quer dizer, frente ao domínio predatório da visão objetificadora do mundo; frente à instrumentalização da vida e à redução do ser humano a material e recurso de manipulação; frente à perda de 


\section{Ism otlltaráo

ISSN: 1984-6444 | http://dx.doi.org/10.5902/1984644435113

dignidade que decorre do trabalho técnico desumanizado; frente à burocratização das relações humanas; frente a toda essa barbárie do mundo técnico-científico, que tira o espaço da liberdade e esvazia a originalidade da existência individual, os humanismos tradicionais não podem oferecer qualquer alento. Não podem justamente porque são parte essencial desse movimento metafísico que a técnica e a ciência moderna apenas expressam de forma mais acabada. E, nesse ponto, há de se entender que "o fato de a técnica se apresentar como uma ameaça para a metafísica e para o humanismo é apenas uma aparência, derivada de que, na essência da técnica, desvendam-se as características próprias da metafísica e do humanismo, que estes sempre haviam mantido ocultas" (VATTIMO, 1996, p. 29).

Como parte essencial do pensamento metafísico que o mundo tecnológico expõe em sua versão mais radical, o humanismo não pode oferece um horizonte reflexivo suficientemente amplo para que se possa pensar até o fundo a realidade em que o ser humano se encontra imerso a cada vez, dando-lhe, desse modo, condições de realizar suas melhores possibilidades no momento histórico em que se encontra. Por isso que, pela perspectiva de Heidegger, apenas um pensamento que renuncia ao humanismo e a seus esquemas metafísicos de representação do mundo, pode contribuir para que se compreenda amplamente a dinâmica das sociedades contemporâneas (e suas experiências terríveis) a ponto de devolver ao ser humano algum poder de decisão em relação ao seu futuro.

É nesse ponto, precisamente, diante das limitações do humanismo frente ao perigo que emana da essência da técnica, que Heidegger afirma a urgência do pensamento do ser, enquanto atenção aos pressupostos históricos que orientam nossa experiência e nossa compreensão de mundo. Sendo assim, o mérito desse outro jeito de pensar, se é que pode reivindicar algum, é o de relativizar a perspectiva técnico-científica, fazendo-a aparecer como uma forma dentre outras que o ser humano tem de interpretar no mundo. ${ }^{6}$

O pensamento do ser representa também, nesse sentido, uma abertura alternativa para se pensar a condição humana para além dos círculos traçados pelo humanismo. E pensar além dos limites postos pelo humanismo inclui, sobretudo, pensar aquém do círculo da subjetividade. ${ }^{7} \mathrm{O}$ problema com a subjetividade, vale 


\section{N Wsy otlltaráo

ISSN: 1984-6444 | http://dx.doi.org/10.5902/1984644435113

ressaltar, é que foi em torno dela que se edificou o paradigma da objetividade, o qual, com o desenvolvimento da técnica e da ciência modernas, acabou por converter o próprio sujeito em objeto. Afinal, só na perspectiva de uma subjetividade irrestrita é que se levanta a perspectiva de uma objetividade irrestrita. Foi assim que a realidade foi se afastando paradoxalmente da perspectiva humana e ganhando ares de independência. É precisamente contra essa perspectiva incondicionada e fatalista da realidade que Heidegger se rebela. E é esse Heidegger "rebelde" que, segundo Vattimo (2016), pode contribuir mais significativamente para a compreensão e transformação do nosso mundo.

Também para os propósitos de pensar a formação humana para além dos humanismos interessa, sobretudo, essa veia rebelde da filosofia heideggeriana. Que Heidegger possa ser lido nessa perspectiva, isso se justifica na medida em que se puder entender adequadamente a crítica do filósofo à metafísica, exposta até aqui, enquanto recusa da crença em uma estrutura objetiva da realidade. A partir dessa chave interpretativa, até mesmo a polêmica que Heidegger levanta, em Ser e tempo, contra o conceito tradicional de verdade ganha sentido enquanto combate à visão determinista do mundo que ameaçava se consolidar através da expansão do discurso positivista. Afinal, caso se tivesse que reconhecer que há uma estrutura objetiva da realidade, como aquela que na sociedade técnico-científica moderna aparece como uma ordem racional em que tudo está disposto e ordenado de forma consequente, então o conhecimento e o comportamento humanos teriam de ser validados a partir da correspondência a essa estrutura. O que é o ser humano e qual a sua função no mundo ficaria decidido a partir da suposta objetividade do mundo, tolhendo-se com isso toda a liberdade e a originalidade da existência humana. É como reação a essa condição que se deve interpretar a insistência de Ser e tempo em falar de uma verdade mais originária, de uma abertura de sentido que precisa ser assumida como condição de possibilidade das verdades proposicionais; para Vattimo (2016, p. 44), não há outra explicação para essa polêmica em torno da verdade, senão essa motivação prática-política de questionar a ordem vigente.

Em favor de sua interpretação, Vattimo (2016, p. 110) faz alusão ainda ao fato de Heidegger, em Ser e tempo, recusar a assunção da história como um vergangen ${ }^{8}$, 


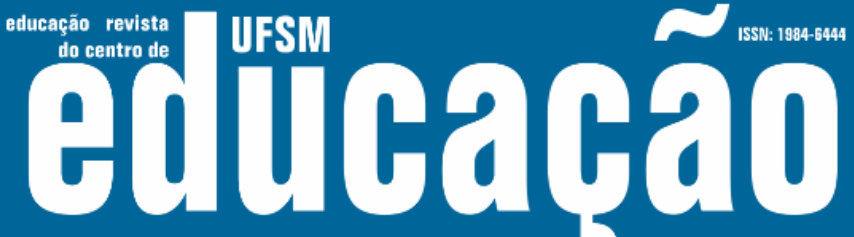

ISSN: 1984-6444 | http://dx.doi.org/10.5902/1984644435113

como uma herança que não se pode senão aceitar - palavra de ordem de todo tradicionalismo, de toda posição conservadora. Isso seria, na visão de Vattimo, uma evidência adicional de que sua perspectiva teórica pende para o lado daquilo que, em tempos menos obscuros do que os atuais, se chamava de "revolução permanente".

Assumida e demarcada essa linha interpretativa do pensamento heideggeriano, convém enfrentar, agora, a questão sobre como retirar dela diretrizes para se pensar a formação humana. Como o pensamento do ser, e sua vocação rebelde, pode preencher o vazio normativo deixado pela rejeição do humanismo em suas formulações tradicionais? Antes de enfrentar essa questão, porém, cabem ponderações sobre a própria viabilidade de ainda se falar em formação, considerando o vínculo estreito desse conceito com o humanismo. De fato, junto à crise da metafísica e do humanismo, também entra em crise, no entender de Heidegger (2006c), a ideia tradicional de formação. ${ }^{9}$ Tanto quanto a metafísica e o humanismo, também "a época da formação se aproxima do fim" (HEIDEGGER, 2006c, p. 59). Mas isso não deve ser interpretado apressadamente. Em linha com o que se defendeu até aqui, o anúncio do fim da formação fala apenas do fim do modelo humanísticometafísico de formação. ${ }^{10} \mathrm{Fala}$, portanto, contra aquela pretensão metafísica de apresentar ao ser humano "um modelo para servir de parâmetro à sua ação e omissão" (HEIDEGGER, 2006c, p. 58) e não contra o interesse pelo cultivo e cuidado da essência humana. Se o fim da formação ao estilo metafísico não representa o fim do interesse pela essência humana, então ainda permanece a questão sobre o que significa cuidar do humano numa perspectiva não humanista.

Uma ideia inicial (e ainda precária) de como poderia ser concebida a formação humana numa perspectiva pós-metafísica e pós-humanista pode ser visualizada a partir da convocação heideggeriana ao pensamento do ser. Pensar o ser, esquecido pela tradição, é o caminho para uma relação mais livre com a metafísica e com tudo o que está ameaçadoramente vinculado a ela - o domínio planetário da técnica, a objetificação do ser humano etc. Isso porque, como já foi assinalado anteriormente, o pensamento do ser é a recordação de que há um estofo histórico-cultural de sentido que determina o modo como se compreende e se experiencia o mundo. $O$ pensamento que recorda do ser cumpre, assim, a tarefa de relativizar a força das 


\section{Authab̧ão}

ISSN: 1984-6444 | http://dx.doi.org/10.5902/1984644435113

verdades e, consequentemente, das estruturas vigentes. Um pensamento que se esforça para sair do esquecimento do ser (e, assim, da identificação do ser com o objeto) é o único que, no entender de Vattimo (2016, p. 45), "empenha e envolve antes de tudo o ente [humano] que se esforça para realizar essa operação". Esse é o traço formativo geral do pensamento do ser: por meio desse pensar tem lugar um envolvimento interpretativo com a realidade que põe em perspectiva o conjunto das possibilidades humanas, revelando-as em sua exata condição de possibilidades.

Enquanto resistência ao domínio das verdades metafísicas e de suas determinações existenciais, o pensamento do ser não oferece nenhuma verdade alternativa, pretensamente mais verdadeira. A luta contra a metafísica, contra humanismo e contra a noção tradicional de formação, é a luta pela liberdade radical que pertence à essência humana enquanto abertura para o ser, isto é, enquanto abertura para o horizonte mais primitivo de articulação do sentido de tudo o que é e pode ser. $\mathrm{O}$ ser humano constitui-se sempre a partir de um mundo, e o pensamento do ser lembra que esse mundo também é um evento histórico que o ser humano não controla em absoluto, mas que pode influenciar a partir de suas decisões. Pensar o ser é, nessa perspectiva, empenhar-se efetivamente na construção de um projeto histórico coletivo e, portanto, político, que forneça o horizonte para a projeção de cada existência singular. Aqui se decide a autenticidade e a inautenticidade do existir; aqui, portanto, convém falar de formação.

Em um esforço para tornar mais palpável o caráter formativo disso que Heidegger chama de pensamento do ser, pode-se remeter àquilo que Vattimo (2016, p. 45) chamou, em uma referência livre ao pensamento de Foucault, de "ontologia da atualidade". Para ele, o pensamento do ser conduz a uma ontologia da atualidade na medida em que busca "reconhecer os traços específicos da abertura histórica em que estamos lançados", ao mesmo tempo em que busca "reconhecer sua radical contingência e historicidade, com uma espécie de distanciamento que talvez seja para Heidegger o verdadeiro sentido da epoché fenomenológica" (VATTIMO, 2016, p. 45). Nesse movimento pensante em direção à própria historicidade, abre-se para o ser humano os caminhos existenciais para a construção de si mesmo, de modo que sua vida não seja um mero reflexo das forças históricas de seu tempo. 


\section{Autharẫ}

ISSN: 1984-6444 | http://dx.doi.org/10.5902/1984644435113

É voltando-se para a ordem vigente, a fim de identificar seus pressupostos histórico-culturais, que o ser humano pode manter aberto o espaço livre de articulação de novos sentidos, sendo aquilo que Heidegger (2005, p. 34) chamou de "pastor do ser", aquele que cuida para que o mundo (o "aí" da existência) permaneça justamente uma abertura, um campo de jogo para as possibilidades futuras, e não se cristalize em um conjunto limitado de formas e fórmulas - a antiessência da existência (e da formação).

Com isso libera-se uma perspectiva para se pensar a formação que evita aquele tipo de pressuposto essencialista-idealista que há muito vem marcando a história do debate em torno da educação, mas que já não faz sentido no contexto cultural das sociedades plurais, em que a polivalência de concepções de mundo, de posturas éticas, religiosas e filosóficas divergentes reclama direitos iguais. Como observa Goergen (2017, p. 446), "pressupõe-se, atualmente, que devem ser admitidas respostas não convergentes sobre o que é o homem, a sociedade e a verdade". A perspectiva formativa aberta pela crítica heideggeriana à metafísica e ao humanismo atende tal pressuposto e, nisso, se mostra mais adequada as demandas éticas e políticas das sociedades plurais da atualidade. Ao rejeitar toda sorte de ideais intrínsecos e extrínsecos que de alguma forma demarcam um limite para a liberdade ontológica do ser humano, a formação pós-humanista orientada para uma ontologia da atualidade torna-se uma formação em favor da diferença.

\section{Conclusão}

A Carta sobre o humanismo de Heidegger é uma defesa de um modo de pensar o ser humano sem "-ismos", quer dizer, sem as categorias da tradição metafísica; um modo de pensar a essência do humano a partir de sua abertura ao sentido ser. Em outras palavras, significa um modo pensar o ser humano desde a totalidade de seu acontecer no mundo, desde sua pertinência a um tempo, a uma história. Isso tudo é bloqueado pelo humanismo metafísico, quando este, em suas diferentes formulações, inicia a reflexão sobre o ser humano fixando pressupostos sobre sua natureza, sua história e seu mundo. 


\section{Autharẫ}

ISSN: 1984-6444 | http://dx.doi.org/10.5902/1984644435113

A crítica de Heidegger ao humanismo não recusa o interesse de afastar o ser humano da selvageria, da barbárie que de tempos em tempos espreita a humanidade; só não pretende fazê-lo a partir de um ideal universal de ser humano. Por mais ampla que possa ser, a demarcação de ideais é sempre uma limitação às possibilidades humanas. Como bem observa Foucault (2008, p. 150), na passagem selecionada como epígrafe deste escrito, há sempre mais segredos, mais liberdades possíveis e mais invenções no futuro da humanidade do que se poderá imaginar a partir de um humanismo qualquer. ${ }^{11}$ Disso não se segue, contudo, uma falta absoluta de critérios, que deixa o ser humano entregue aos ventos das decisões arbitrárias.

O comprometimento com o pensamento do ser, que na interpretação de Vattimo aparece como uma ontologia da atualidade, vincula o ser humano com a efetividade de um mundo já constituído e que tem a tradição como critério (talvez único) para compreensão do presente e a projeção do futuro. Assim, uma ontologia da atualidade, que garanta ao ser humano a abertura radical de suas possibilidades, só alcança seu direito por meio de um diálogo verdadeiro com o passado. Todo empenho com o presente e todo projeto de futuro que se constitui na ignorância do passado guarda em si o risco das decisões arbitrárias e míopes; ao contrário do que poderia parecer de imediato, não é o abandono do passado, mas a sua recuperação criativa que garante a originalidade do futuro, enquanto horizonte para o novo.

Por fim, cabe observar que o pensamento do ser, enquanto alternativa à metafísica, ao humanismo e a formação tradicional, não oferece elementos práticos receitas ou métodos - para a formação humana, seja em termos de uma educação formal ou informal. Ainda assim, é preciso reconhecer que esse pensamento abre outras possibilidades e oferece outros critérios para avaliar e decidir sobre tudo o que é prático em relação à educação humana: sobre os méritos ou os deméritos uma escola tecnicista, sobre a utilidade ou a inutilidade de disciplinas reflexivas, sobre o espaço e o valor da tradição cultural, enfim, sobre o próprio sentido da educação e seu papel (ético-político) na transformação social. 


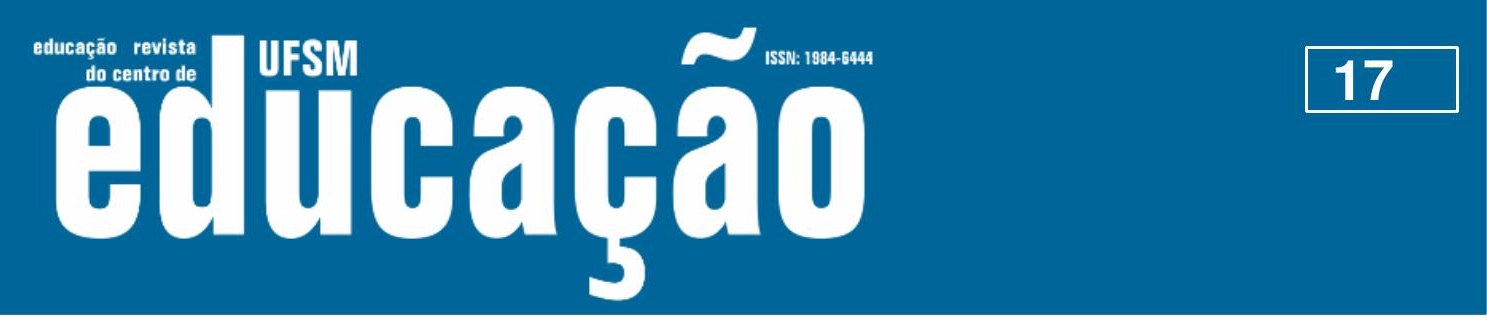

ISSN: 1984-6444 | http://dx.doi.org/10.5902/1984644435113

\section{Referências}

FOUCAULT, Michel. Tecnologías del yo y otros textos afines. Buenos Aires: Paidós, 2008. (Pensamiento contemporâneo, 7)

GOERGEN, Pedro. Bildung ontem e hoje: restrições e perspectivas. Espaço Pedagógico, Passo Fundo, v. 24, n. 3, p. 437-451, set./dez. 2017. Disponível em: seer.upf.br/index.php/rep/article/viewFile/7758/4590. Acesso em: mar. 2018.

HEIDEGGER, Martin. A constituição onto-teo-lógica da metafísica. In: HEIDEGGER, Martin. Conferências e escritos filosóficos. São Paulo: Nova Cultural, 1999a, p. 185-200. (Col. Os pensadores)

HEIDEGGER, Martin. A questão da técnica. In: HEIDEGGER, Martin. Ensaios e conferências. 3. ed. Petrópolis: Vozes; Bragança Paulista: Editora Universitária São Francisco, 2006a, p. 11-38.

HEIDEGGER, Martin. A superação da metafísica. In: HEIDEGGER, Martin. Ensaios e conferências. 3. ed. Petrópolis: Vozes; Bragança Paulista: Editora Universitária São Francisco, 2006b, p. 61-86.

HEIDEGGER, Martin. A teoria platônica da verdade. In: HEIDEGGER, Martin. Marcas do caminho. Petrópolis: Vozes, 2008, p. 215-250.

HEIDEGGER, Martin. Carta sobre o humanismo. 2. ed. rev. São Paulo: Centauro, 2005.

HEIDEGGER, Martin. Ciência e pensamento do sentido. In: HEIDEGGER, Martin. Ensaios e conferências. 3. ed. Petrópolis: Vozes; Bragança Paulista: Editora Universitária São Francisco, 2006c, p. 39-60.

HEIDEGGER, Martin. O fim da filosofia e a tarefa do pensamento. In: HEIDEGGER, Martin. Conferências e escritos filosóficos. São Paulo: Nova Cultural, 1999b, p. 95-108. (Col. Os pensadores).

HEIDEGGER, Martin. Sein und Zeit. 16 ed. Tübingen: Max Niemeyer, 1986.

HEIDEGGER, Martin. Ser e tempo. 4. ed. Petrópolis: Vozes, 2009.

HOYOS-VÁSQUEZ, Guillermo. Educación para un nuevo humanismo. Magis Revista Internacional de Investigación en Educación, [S.I.], v. 1, n. 2, sep. 2012. Disponível em: http://revistas.javeriana.edu.co/index.php/MAGIS/article/view/3395. Acesso em: 14 maio 2017. 


\section{W usm Fillbap̧a}

ISSN: 1984-6444 | http://dx.doi.org/10.5902/1984644435113

KANT, Immanuel. Crítica da razão pura. Trad. Valerio Rohden e Udo Baldur Moosburger. 2. ed. São Paulo: Abril Cultural, 1983. (Os pensadores).

NIETZSCHE, Friedrich Wilhelm. Fragmentos póstumos, v.6. Rio de Janeiro: Forense, 2013.

SLOTERDIJK, Peter. Reglas para el parque humano: una respuesta a la "Carta sobre el Humanismo". Revista Observaciones Filosóficas [S.I.], n. 5, 2007. Disponível em:

http://www.observacionesfilosoficas.net/petersloterdijkdelasnormas.html. Acesso em: 14 maio 2017.

STEIN, Ernildo. Inovação na filosofia. ljuí: Ed. Unijuí, 2011.

SUÁREZ, Luisa P. R. Pensar más allá del humanismo com Nietzsche, Heidegger y Foucault. Studium - Revista de Humanidades, Zaragoza, n. 13, p. 185-198, 2007. Disponível em: https://dialnet.unirioja.es/descarga/articulo/2542178.pdf. Acesso em: 19 maio 2017.

VATTIMO, Gianni. Adeus à verdade. Petrópolis: Vozes, 2016.

VATTIMO, Gianni. O fim da modernidade: niilismo e hermenêutica na cultura pósmoderna. São Paulo: Martins Fontes, 1996.

\section{Correspondência}

Marcelo José Doro - Universidade de Passo Fundo, Instituto de Filosofia e Ciências Humanas, BR 285, São José, CEP 99052-900, Passo Fundo, Rio Grande do Sul, Brasil.

\section{Notas}

${ }^{1}$ Heidegger está consciente da existência desse movimento circular, mas alerta para que não seja confundido com um círculo vicioso: "[...] ver nesse círculo um vício, buscar caminhos para evitá-lo e também 'senti-lo' apenas como imperfeição inevitável, significa um mal-entendido de princípio acerca do que é compreender. [...] O decisivo não é sair do círculo, mas entrar nele de modo adequado." (HEIDEGGER, 1986, p. 153)

${ }^{2}$ Em Ser e tempo, a ideia é apresentada inicialmente no § 9, onde é dito "a 'essência' do ser-aí (Dasein) está em sua existência" (HEIDEGGER, 1986, p. 42). "Essência" aparece entre aspas, porque não tem o sentido tradicional de algo intrínseco ao próprio ente. Mas essência ou substância também indica, tradicionalmente, aquilo que permanece constante, como tal, determina o que cada coisa é em seu ser. É apenas nesse sentido que se pode falar de uma "essência" ou "substância" humana. No § 25 de Ser e tempo, a ideia reaparece com uma roupagem um pouco diferente: "a 'substância' do ser humano é a existência" (HEIDEGGER, 1986, p. 117); essa mesma formulação será repetida, depois, no § 43 e no $\S 63$ de Ser e tempo. Na Carta sobre o humanismo, a ideia é retomada para a explicitação de em seu sentido fundamental (HEIDEGGER, 2005, p. 25). 


\section{usm Eutlaghã}

ISSN: 1984-6444 | http://dx.doi.org/10.5902/1984644435113

${ }^{11}$ Essas ressalvas de Foucault em relação ao humanismo aparecem na entrevista que o filósofo francês concede durante sua passagem pela Universidade de Vermont, em outubro de 1982. Antecedendo o trecho transcrito, há uma importante reflexão sobre o sentido da relativização do humanismo - que foi provocada por uma pergunta sobre a relação entre a normatização e o conceito de ser humano como centro do conhecimento: "Cierta idea o modelo de humanidad ha ido desarrollándose a través de estas distintas prácticas - psicológica, médica, penitencial, educacional - y ahora la idea de hombre se ha vuelto normativa, evidente, y supuestamente universal. Puede que el humanismo no sea universal, sino bastante relativo a cierto tipo de situación. Lo que llamamos humanismo ha sido utilizado por marxistas, liberales, nazis, católicos. Esto no significa que tengamos que eliminar lo que llamamos derechos humanos o libertad, sino que no podemos decir que la libertad o los derechos humanos han de limitarse a ciertas fronteras. Por ejemplo, si se llega a preguntar hace ochenta años si la virtud femenina era parte del humanismo universal, todo el mundo hubiera dicho que sí" (FOUCAULT, 2008, p. 149-150).

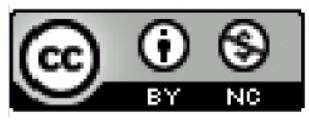

This work is licensed under a Creative Commons Attribution-NonCommercial 4.0 International (CC BY-NC 4.0) 